\title{
UMA TEORIA DAS FONTES DO DIREITO ROMANO: GENEALOGIA HISTÓRICA DA METÁFORA
}

\section{A THEORY OF THE SOURCES OF ROMAN LAW: HISTORICAL GENEALOGY OF THE METAPHOR}

\author{
Walter Guandalini Junior \\ Universidade Federal do Paraná - UFPR (Curitiba, PR, Brasil)
}

Recebimento: 10 jun. 2016

Aceitação: 22 mar. 2017

\begin{abstract}
Como citar este artigo / How to cite this article (informe a data atual de acesso / inform the current date of access):
GUANDALINI JUNIOR, Walter. Uma teoria das fontes do direito romano: genealogia histórica da metáfora. Revista da Faculdade de Direito UFPR, Curitiba, PR, Brasil, v. 62, n. 1, jan./abr. 2017, p. 9 - 31. ISSN 2236-7284. Disponível em: <http://revistas.ufpr.br/direito/article/view/47101>. Acesso $\quad$ em: $30 \quad$ abr. $2017 . \quad$ DOI: http://dx.doi.org/10.5380/rfdufpr.v62i1.47101.
\end{abstract}

\section{RESUMO}

O artigo pretende realizar uma revisão do tratamento teórico dado pela romanística tradicional ao estudo das fontes do direito romano: sem abrir mão do seu caráter especificamente dogmático, e evitando recair em concepções transcendentais, retoma as classificações tradicionais como instrumento heurístico para uma abordagem historicamente consciente, que busca enfatizar o caráter polêmico inerente a toda sistematização de fontes do direito. Desse modo, a partir de uma genealogia histórica dos diferentes significados atribuídos à metáfora da "fonte do direito" na antiguidade, e de uma compreensão histórica das disputas políticas concretas em torno do processo de formalização de normas jurídicas em qualquer sociedade humana, pretende-se demonstrar que o trabalho de identificação das fontes do direito romano não pode ser tomado como ponto de partida, mas sempre como resultado final da pesquisa histórico-jurídica - obrigada a investigar, para compreendê-las, as condições materiais de formalização do direito disponíveis para a sociedade romana antiga. A abordagem permite compreender o duplo aspecto constituinte-constituído das fontes do direito romano, e poderá contribuir para um melhor entendimento do emaranhado processo histórico de construção de um ordenamento jurídico autônomo pela sociedade romana antiga.

\section{PALAVRAS-CHAVE}

Direito romano. História do direito. Fontes do direito romano.

\begin{abstract}
This paper proposes a change of treatment on the studies about the sources of Roman law: preserving its specifically dogmatic nature, but also avoiding a transcendental legal reasoning, it proposes the resumption of traditional classifications as a heuristic tool to a historically conscious approach of the issue, which emphasizes the controversial character of every systematization of legal sources. Thus, departing from a historical genealogy of the different meanings attributed to the metaphor of "source of law" in antiquity, and from a historical understanding of the concrete political disputes around the process of legal rules formalization in any human society, it intends to demonstrate that the identification of the sources of Roman law can not be taken as a starting point, but always as the final
\end{abstract}


result of legal-historical research - which is compelled to investigate, in order to understand them, the material conditions of legal formalization available to ancient Roman society. This approach allows us to understand the dual constituent-constituted aspect of the sources of Roman law, and may contribute to a better understanding of the mazy historical process of construction of an autonomous legal order by ancient Roman society.

\section{KEYWORDS}

Roman law. Legal history. Sources of Roman law.

\section{INTRODUÇÃo}

A tradição romanística costuma classificar as fontes do direito romano em fontes de conhecimento e fontes de produção. As fontes de conhecimento são identificadas com as fontes de pesquisa historiográfica, ou seja, aqueles elementos que podem contribuir, no presente, para a compreensão das características do direito romano antigo - fontes literárias, documentais, epigráficas, papirológicas, numismáticas, iconográficas, arqueológicas, etc. Já as fontes de produção se associam ao que a dogmática contemporânea compreende como as formas de manifestação das prescrições jurídicas - análogas às que são, em nosso ordenamento, identificadas com a lei, a jurisprudência, a doutrina e os costumes.

O presente artigo pretende contribuir para a compreensão das fontes de produção do direito romano. Desse modo, deixa de lado os instrumentos disponíveis à análise histórica do direito romano para se concentrar no estudo do modo como as prescrições jurídicas se manifestam na sociedade romana antiga -, tratando as fontes do direito romano em sentido dogmático, como tradicionalmente definidas pela teoria geral do direito:

Os processos ou meios em virtude dos quais as regras jurídicas se positivam com legítima força obrigatória, isto é, com vigência e eficácia no contexto de uma estrutura normativa (REALE, 2001, p. 130).

No entanto, a escolha da perspectiva não pode justificar uma análise estritamente dogmática das fontes do direito romano, que se limite a sistematizar os modos de produção de regras jurídicas aceitos pela estrutura normativa então vigente. Pelo contrário, este trabalho deseja realizar uma abordagem histórico-crítica de um problema dogmático-jurídico: pretende-se refletir sobre aspectos teóricos e metodológicos relativos à possibilidade de compreensão histórica dos modos de elaboração de regras jurídicas entre os romanos da antiguidade. Em outras palavras, não apenas enumerar as vias formais de produção do direito romano, mas sugerir premissas teóricas simples que possam contribuir para a compreensão do processo material de formalização do direito, do regime de transformação de 
interesses contrapostos em normas cogentes, e dos modos de concentração de tais instrumentos nas mãos de determinados grupos sociais durante a história da civilização romana.

Dessa forma, propõe-se a superação do modo usual como a tradição romanística costuma tratar do problema das fontes de produção do direito romano, em prol de uma abordagem históricojurídica do tema: uma abordagem que permita enxergar o modo específico como o ordenamento jurídico se formaliza entre os romanos, sem diluir as fontes do direito no oceano do social nem confundi-las com as suas fontes de conhecimento (como faria uma pesquisa estritamente histórica), mas uma abordagem que também permita uma compreensão mais claramente material do processo histórico de formalização de regras jurídicas com legítima força obrigatória no contexto da estrutura normativa romana antiga, sem encerrar a análise no limite das fontes formais existentes e reconhecidas. Em suma, que torne possível perceber a produção e reprodução do direito romano como processo histórico de formalização jurídica de interesses materiais concretos.

Para isso, após uma descrição panorâmica do modo como a tradição romanística costuma abordar o problema, suas limitações serão avaliadas de uma perspectiva histórica que apresentará duas premissas teóricas fundamentais para o tratamento histórico-jurídico das fontes do direito romano. Ao final, pretende-se demonstrar de que maneira essas premissas podem contribuir para uma compreensão mais complexa do processo de construção da ordem jurídica romana.

\section{AS FONTES COMO ORIGEM: ABORDAGEM DOGMÁTICA}

\subsection{CLASSIFICAÇÃO SISTEMÁTICA}

Tradicionalmente, os livros-texto de direito romano costumam abordar as suas fontes de uma perspectiva estritamente formal-normativa ${ }^{1}$. Profundamente influenciados pela teoria contemporânea do direito privado e pela atual dogmática civilista, não se preocupam em avaliar o peso relativo de cada uma das fontes conforme o desenvolvimento histórico da sociedade romana, mas se limitam a apresentar um quadro formal das várias fontes de produção do direito em Roma, organizadas em um sistema estático e dogmático. Para isso, usualmente se fundamentam na classificação elaborada por Gaio em suas Instituições, em que o jurista indica como fontes do direito romano as leis, os plebiscitos, os senatusconsultos, as constituições imperiais, os editos dos magistrados e as respostas dos jurisconsultos:

\footnotetext{
${ }^{1}$ É o que fazem na doutrina brasileira, por exemplo, Ebert Chamoun (1957), Antônio Filardi Luiz (1999), Thomas Marky (2010) e Bruno Albergaria (2012), apenas para citarmos as obras mais populares. Em menor medida, também José Carlos Moreira Alves, apesar de uma preferência clara pela abordagem cronológica (2012, p. 86).
} 
I.2. As fontes dos direito do povo romano são: as leis, os plebiscitos, os senátus-consultos, as constituições imperiais, os editos dos magistrados que possuem o direito de emitir editos, as respostas dos jurisprudentes (GAIO, 2010, p. 77).

Volta e meia se incluem também nessa classificação os costumes, não citados por Gaio mas extraídos de fragmentos de Juliano, Ulpiano, Hermogeniano, Paulo, Calístrato e Modestino, compilados no Digesto:

D.1.3.32. [Juliano] Quanto às causas para as quais não temos leis escritas, é preciso observar o que foi introduzido pelos mores e pela consuetudo. E se em alguma coisa isto for deficiente, então se observe o que lhe for mais próximo e consequente; se na verdade nem isso houver, então se deve observar o direito do qual a cidade de Roma se utiliza (MADEIRA, 2012, p. 57).

A partir dessa classificação, as fontes são conceituadas com base em sua forma de elaboração e definidas em uma sistematização panorâmica dos modos de produção do direito em Roma. Os elementos da definição são extraídos do próprio texto de Gaio, exceto pelo costume - justificado por Juliano e Hermogeniano com fundamento no “consenso tácito” dos cidadãos, que ao observarem espontaneamente certas normas de comportamento social lhes conferem a força cogente necessária para que se transformem em direito:

D.1.3.32.1. [Juliano] O costume (consuetudo) inveterado não é guardado despropositadamente, e este é o direito que se diz constituído pelos mores. Pois, uma vez que as próprias leis não nos obrigam senão pelo fato de que foram admitidas pelo juízo do povo, com razão também obrigarão a todos estas coisas que o povo aprovou sem sequer um escrito. Pois o que importa ao povo declarar a sua vontade por sufrágio ou por meio dos próprios fatos e feitos? Por isso também foi corretíssimo admitir que as leis sejam ab-rogadas não só pelo sufrágio do legislador, mas também pelo tácito consenso de todos por meio do desuso (MADEIRA, 2012, p. 57).

Após o costume, a apresentação das fontes do direito romano não é mais acompanhada de uma justificativa teórica das razões de sua validade; apenas são identificadas, a partir de Gaio (2010, p. 77-78), com base na autoridade a que se reconhece a prerrogativa de as produzir. Assim, leis e plebiscitos são definidos em conjunto, como o resultado da vontade política de criar normas jurídicas, respectivamente, por todo o povo romano reunido em comícios, ou apenas pela plebe reunida em concílios; senatusconsultos são resultado de determinações do senado; constituições imperiais são resultado de determinações do imperador; editos dos magistrados são resultado de determinações dos magistrados “que possuem o direito de emitir editos” (pretores e edis curuis); e respostas dos jurisconsultos são resultado de pareceres emitidos por juristas com fundamento em sua autoridade moral e científica.

Eventualmente se apresentam especificações ulteriores. Discute-se o papel subordinante ou subsidiário do costume em relação à lei. Informa-se que a lei pode ser rogata ou data, conforme tenha 
sido proposta pelo magistrado à assembleia comicial ou por ele dada no exercício de delegação recebida do comício; que é composta por três partes básicas (praescriptio, rogatio e sanctio) e que foi classificada por Ulpiano em perfectae, minus quam perfectae e imperfectae, com base na gravidade das sanções aplicáveis em caso de violação (nulidade do ato, punição, ausência de sanção). Explica-se que o plebiscito apenas adquire caráter vinculante para todo o povo com a Lex Hortensia, de 287 a.C., enquanto a imperatividade dos senatusconsultos é construída paulatinamente sobre a auctoritas patruum dos pareceres emitidos pelos senadores. Classificam-se as constituições imperiais em editos, decretos, rescritos e mandatos, esclarecendo-se que por ordem do imperador Adriano os editos dos magistrados foram cristalizados no edictum perpetuum, e que ainda durante o governo de Augusto reconheceu-se maior autoridade às respostas de alguns jurisconsultos, agraciados pelo imperador com o direito de responder com sua autoridade - ius respondendi ex auctoritate principis ${ }^{2}$.

Essas especificações tornam mais precisa a sistematização das fontes, mas não são suficientes para se compreender a sua posição no contexto do ordenamento jurídico romano. A classificação dogmática tem limitações evidentes, que nos impedem de observar adequadamente o modo como o direito se formaliza na sociedade romana antiga.

Em primeiro lugar, é importante recordar que o documento histórico em que a classificação se baseia (as Instituições de Gaio) foi redigido em um contexto histórico específico, e reflete o sistema de fontes desse contexto. As Instituições foram escritas em meados do século II d.C., quando o imperador começava a concentrar poder político e jurídico em torno de si, excluindo progressivamente a nobreza tradicional de quaisquer possibilidades de exercício efetivo de poder político - inclusive a produção do direito. Como explica Schiavone (2005, p. 328), nesse período a jurisprudência se encontrava diante de uma nova realidade na produção do direito: de um lado o exaurimento do ius honorarium, já codificado em um texto imutável (o edito perpétuo); de outro, a oficialização das respostas dos jurisconsultos pela institucionalização do ius respondendi, por meio do qual o imperador colonizava politicamente as respostas proferidas por juristas de sua confiança. A conjuntura permite uma presença cada vez maior de provimentos do príncipe (constituições imperiais), fixando regras que não podem ser ignoradas e que acabam assumindo uma função preponderante em relação às demais fontes existentes.

O papel nuclear do imperador no sistema de produção normativa pode ser percebido com clareza no texto de Gaio (2010, p. 77), que ao mesmo tempo que ressalta as “controvérsias” passadas

\footnotetext{
${ }^{2}$ Seguem esse procedimento todos os autores já mencionados na nota 1: Ebert Chamoun (1957), Antônio Filardi Luiz (1999), Thomas Marky (2010), Bruno Albergaria (2012) e José Carlos Moreira Alves (2012).
} 
acerca da imperatividade dos senatusconsultos (I.4), enfatiza que "nunca foi posto em dúvida que uma constituição imperial possuísse força de lei” (I.5), além de definir as respostas dos jurisprudentes como os pareceres daqueles “a quem é permitido” (pelo imperador) ser fonte de direito. Como explica Schiavone (2005, p. 330), o fio condutor de seu discurso é o sujeito oculto por detrás da lei: o "povo romano", que aprova as leis e os plebiscitos e legitima as demais fontes citadas (possuem "força de lei”), atribuindo a integralidade de seu poder ao imperador “através de uma lei”. Nesta imagem, a produção normativa proveniente da nobreza aparece completamente encerrada nas malhas da autoridade imperial, apresentando-se o primado do príncipe e da sua legislação como realidade insuperável.

É evidente, portanto, a influência do contexto específico da sociedade romana do século II d.C. na classificação organizada por Gaio em suas Instituições. Isso, por si só, não precisa ser um problema, sob a condição de que não esqueçamos que a classificação fornece apenas uma fotografia, e uma fotografia de um período muito específico da longa história da civilização romana - incapaz, portanto, de revelar com qualidade os 1.300 anos de história de seu ordenamento jurídico. No entanto, ao tomar a classificação de Gaio como enumeração exaustiva das fontes jurídicas romanas, a romanística tradicional ${ }^{3}$ adota como padrão abstrato um sistema de fontes do direito que traduz a realidade específica do período em que o autor escreveu, mas que é incapaz de apresentar as características do sistema de produção jurídica de outros contextos, inquestionavelmente distintos, nos 1.300 anos da longa história do direito na sociedade romana antiga.

\subsection{CLASSIFICAÇÃO CRONOLÓGICA}

Mas da própria abordagem dogmática provém um esquema de classificação alternativo. Talvez inspirados pela narrativa histórica de Pompônio, que no Enchiridion (D.1.2.2) considerou “necessário demonstrar a origem e o desenvolvimento do próprio direito”, os romanistas complementam a classificação sistemática com um plano simplificado de "evolução histórica” das fontes do direito romano. Desse modo, identificam as diversas fases da História Externa da sociedade romana e organizam uma classificação cronológica das fontes conforme o seu peso relativo em cada período histórico específico4: Realeza, República, Principado e Dominato.

\footnotetext{
${ }^{3}$ Dos autores supracitados (notas 1 e 2 ).

${ }^{4}$ Na doutrina brasileira temos os exemplos de Silvio Meira (1975), Mario Giordani (1991), Antônio Filardi Luiz (1999), José Cretella Júnior (2009), Thomas Marky (2010) e José Carlos Moreira Alves (2012).
} 
Informam, então, que durante a Realeza (754 a.C. - 510 a.C.) a fonte de produção normativa predominante eram os costumes, como em "todos os povos primitivos" (ALVES, 2012, p. 11). Esclarecem que o caráter imperativo dos mores maiorum decorre de sua origem mágica, e que a jurisprudência produzida a partir deles é extremamente formalista, sendo controlada pelos pontífices. Acrescentam a tradicional referência à coletânea de leis régias organizada por Sexto Papírio, mas ressalvam que a crítica histórica a considera apócrifa - provavelmente organizada ao final do período republicano, continha editos religiosos outorgados pelos pontífices.

Na República (510 a.C. - 27 a.C.) a lei começa a adquirir importância: primeiro com a elaboração da Lei das XII Tábuas, em 451 a.C., e em seguida com as várias leis comiciais e plebiscitos. A partir do século III a.C. se desenvolvem os editos dos magistrados, que estabelecem novos meios de proteção de direitos e dão origem ao ius honorarium. Na mesma época ocorre a secularização da jurisprudência, o que permite que sejam dados os primeiros passos para a formação de um saber jurídico científico.

Com as transformações políticas do Principado (27 a.C. - 285 d.C.) ocorre o esvaziamento dos comícios legislativos, reduzindo-se a importância das leis e plebiscitos e promovendo-se a transferência do eixo político para as mãos do imperador. O costume passa a se confundir com o ius honorarium dos pretores, que vem a ser cristalizado no Edito Perpétuo de 134, por ordem do imperador Adriano. Os jurisconsultos têm a sua liberdade limitada pelo ius respondendi, por meio do qual o imperador reconhece apenas aos juristas de sua confiança a autoridade para proferir respostas vinculantes. A atividade legislativa é paulatinamente transferida para o imperador, que de início a exerce indiretamente pela proposta de senatusconsultos, e depois ordenando diretamente a redação de constituições imperiais por sua chancelaria.

Por fim, no Dominato (285 d.C. - 565 d.C.) o poder de produção normativa é integralmente concentrado nas mãos do imperador, cuja vontade se torna a única fonte de direito. Essa vontade é expressa por meio das constituições imperiais, que limitam o recurso ao costume e à doutrina (especialmente após a Lei das Citações de 426). A proliferação legislativa acaba conduzindo às compilações e à codificação do direito romano no Corpus Iuris Civilis, dando origem ao período bizantino.

Por vezes essa classificação cronológica das fontes do direito romano é substituída por outra, que abandona o critério externo fundado nas características da constituição política para se fundamentar em um critério interno ao próprio ordenamento jurídico romano, cuja história é dividida em três etapas: o período pré-clássico, o período clássico e o período pós-clássico. 
O período Pré-Clássico (754 a.C. - 149 a.C.) corresponde ao direito antigo, dominado pelos costumes, pela Lei das XII Tábuas e pelas ações da lei. Abarca toda a Realeza e a maior parte da República, até a promulgação da lei Ebúcia (149 a.C.), que reconhece o processo formular, ou até o início do Principado (27 a.C.), conforme a preferência de cada autor. Ao final da República tem início o período Clássico (27 a.C. - 284 d.C.), quando surgem os maiores juristas romanos e se forma um saber jurídico científico, cada vez mais racional e abstrato, baseado nas respostas dos jurisconsultos. O direito romano se distancia dos rituais mágicos do período arcaico e começa a se organizar em torno de conceitos abstratos - promovendo-se uma abstração formalista que viria a se mostrar essencial para a reconstrução do saber jurídico científico pela Escola de Bolonha, na Baixa Idade Média. Com o governo de Diocleciano tem início a decadência do direito romano, no período designado como Pós-Clássico (284 - 530): a concentração de poderes de produção jurídica nas mãos do príncipe faz com que desapareçam os grandes juristas, substituídos por meros compiladores da legislação imperial. A principal fonte do direito são as constituições imperiais, constantemente reorganizadas pelo movimento codificador que acaba dando origem ao Corpus Iuris Civilis.

Como se percebe, também esta classificação cronológica tem limitações importantes, talvez até mais graves do que as da classificação dogmática, pois se apresenta como classificação histórica sem o ser. Afinal, não avalia o jogo real de poderes em disputa e os efeitos sociais da concentração do poder de criação jurídica durante o desenvolvimento da sociedade romana, mas se limita a substituir um sistema de classificação dogmático por quatro, equivalentes às quatro grandes fases da história política romana. Ao fazê-lo, troca uma fotografia por quatro, que permanecem sendo insuficientes para revelar os 1.300 anos de história jurídica de Roma.

Não bastasse, ao vincular a história do direito à história política parte de premissa metodológica inadequada e anacrônica, especialmente para uma sociedade em que o poder de criação do direito não está diretamente vinculado às instituições políticas, como é a sociedade romana. O critério político cria rupturas artificiais na história do direito romano, impedindo a compreensão tanto das transformações existentes no interior de cada grande fase de sua história política (por exemplo, as complexidades dos 500 anos da República ${ }^{5}$ ), quanto das permanências e continuidades entre uma

\footnotetext{
${ }^{5}$ Durante o período da República o direito romano passou por importantes e complexas transformações: de um direito tradicional e ritualista, baseado nos costumes preservados pelos pontífices, para um direito construído politicamente nos comícios e concílios e fundado na lei e nos plebiscitos, que acaba sendo reinserido na tradição do ius civile pela interpretação dos jurisconsultos, em seguida complexificado pelo desenvolvimento do ius honorarium decorrente da atuação jurisprudencial do pretor, e ao final ordenado em um conjunto de conceitos jurídicos abstratos pela ciência jurídica que começa a se sistematizar na transição para o Império.
} 
fase e outra (por exemplo a permanência da tensão entre casuísmo e abstração na racionalidade jurídica mesmo ao final do Império), pois a mudança no direito não depende da mudança política.

Mesmo a classificação interna não escapa ao anacronismo: também por reunir períodos de intensa complexidade em grandes fases sem se preocupar com as transformações em seu interior (o período Pré-Clássico dura mais de 700 anos!), mas principalmente por empregar na classificação um critério anacrônico que se baseia em uma visão presentista do direito romano antigo. Não por acaso, o período clássico é identificado com o período de formação de um saber jurídico científico abstrato, justamente o saber retomado na Europa do ius commune e empregado na reconstrução da ciência jurídica medieval e moderna. Os demais períodos são identificados apenas em relação a ele, como um direito ainda rudimentar e pouco desenvolvido (Pré-Clássico), ou como uma ordem jurídica que já atingiu o seu ápice e iniciou a decadência (Pós-Clássico).

Com isso se perdem as explicações de processo, tão necessárias à adequada compreensão dos modos de produção do direito em sociedades do passado, o que leva um autor erudito como Moreira Alves, por exemplo, a simplificar a formação do direito romano arcaico em afirmações banais e simplificadoras como as de que "todos os povos primitivos começam a reger-se pelo costume” e "Roma não fugiu a essa regra” (ALVES, 2012, p. 12). Perde-se também a compreensão dos conflitos materiais pelo poder de dizer o direito existente em cada momento histórico, o que conduz a uma visão formalista e, consequentemente, metafísica, dos modos de produção do direito na sociedade romana antiga.

Para se compreender adequadamente o sistema de fontes do direito romano é preciso avaliálas de uma perspectiva dinâmica - e, portanto, não dogmática, mas histórica. O capítulo seguinte propõe duas premissas teóricas para uma abordagem desse tipo, que pretende contribuir para uma compreensão adequada do processo histórico de estabelecimento das regras de disciplinamento social na sociedade romana antiga: o reconhecimento da ideia de "fontes do direito" como metáfora, e o seu reconhecimento como campo de disputa política.

\section{AS FONTES COMO DISPUTA: ABORDAGEM HISTÓRICA}

\subsection{PREMISSA TEÓRICA 1: A FONTE COMO METÁFORA}

A primeira premissa teórica consiste em reconhecer o caráter metafórico da expressão “fontes do direito”, algo que a própria romanística dogmática não deixa de fazer: segundo Santos Justo (2006, p. 76), “a expressão fontes do direito é uma metáfora, porque, em rigor, fonte é o lugar onde a água nos aparece: se vê e se pode facilmente recolher”. Porém, a tradição romanística não 
extrai desse reconhecimento todas as suas consequências teóricas e práticas. Ora, se até os conceitos mais técnicos e precisos têm variações semânticas conforme o seu uso em contextos históricos distintos, quanto mais uma expressão dúctil como "fontes do direito”, que mesmo na rigorosa ciência do direito contemporânea não conta com uma definição estritamente “científica”, e exige explicações complementares para que o seu significado seja plenamente compreendido - como as fornecidas por Miguel Reale, que logo após definir o conceito é obrigado a esclarecer que a expressão pressupõe a existência de um poder político centralizado e institucionalizado ao qual se reconhece, de forma exclusiva, o poder de criar direito:

Toda fonte de direito implica uma estrutura normativa de poder, pois a gênese de qualquer regra de direito só ocorre em virtude da interferência de um centro de poder, o qual, diante de um complexo de fatos e valores, opta por dada solução normativa com características de objetividade (REALE, 2001, p. 130, grifo do autor).

Isso faz com que a aplicação irrefletida do conceito a sociedades do passado seja inevitavelmente anacrônica, pois do ponto de vista dogmático a concepção contemporânea funda as suas raízes no pensamento jurídico europeu moderno: ao pressupor uma estrutura centralizada de poder político dotada de autoridade exclusiva para inovar a ordem jurídica vigente, encontra o seu campo semântico no contexto de formação da estrutura estatal moderna e em uma concepção de absolutismo jurídico que se pode reconhecer no Ocidente a partir dos séculos XVII e XVIII, mas absolutamente não existia na sociedade romana antiga.

Desse modo, é apenas razoável imaginar que mesmo nas ocasiões em que os juristas romanos utilizam a expressão “fontes do direito”, referem-se a um fenômeno distinto. Afinal, a civilização romana adota em seus primórdios uma concepção instrumental do direito, segundo a qual o ius aparece como esquema ritual utilizado para se obter um determinado resultado, que extrai a sua imperatividade da reiteração no tempo, e não de uma autoridade legítima fundamental. Nessa perspectiva, passado e presente coexistem em uma ciclicidade imutável, da qual decorrem a repetição do típico e a recusa de toda inovação - característica que inviabiliza, no pensamento jurídico romano antigo, a própria noção de algo como um ponto de origem ou de produção do direito.

De fato, mesmo ao final do Principado, quando a expressão começa a ser utilizada, a metáfora das fontes do direito atende a uma genealogia muito particular. Como demonstram Cerami e Purpura (2007, p. 203), na antiguidade a expressão se relaciona com o tema do bom pastor, fundando-se em concepções orientais de exercício da autoridade. Os autores recordam o exemplo mesopotâmico de Gudea, um dos mais antigos legisladores de que se tem notícia, governador da região de Lagash entre 2144 a.C. e 2124 a.C., e representado em uma estatueta de $61 \mathrm{~cm}$ em calcita 
cinza, encontrada em 1926 por uma escavação arqueológica clandestina. Denominada Gudea com o vaso que jorra, representa o governante em roupas sacerdotais, vestindo gorro e túnica, e segurando um vaso em suas mãos. Sobre a roupa aparece uma dedicatória à deusa da água vivificante, Geshtinanna, e do vaso jorram água e pequenos peixes, talhados na pedra.

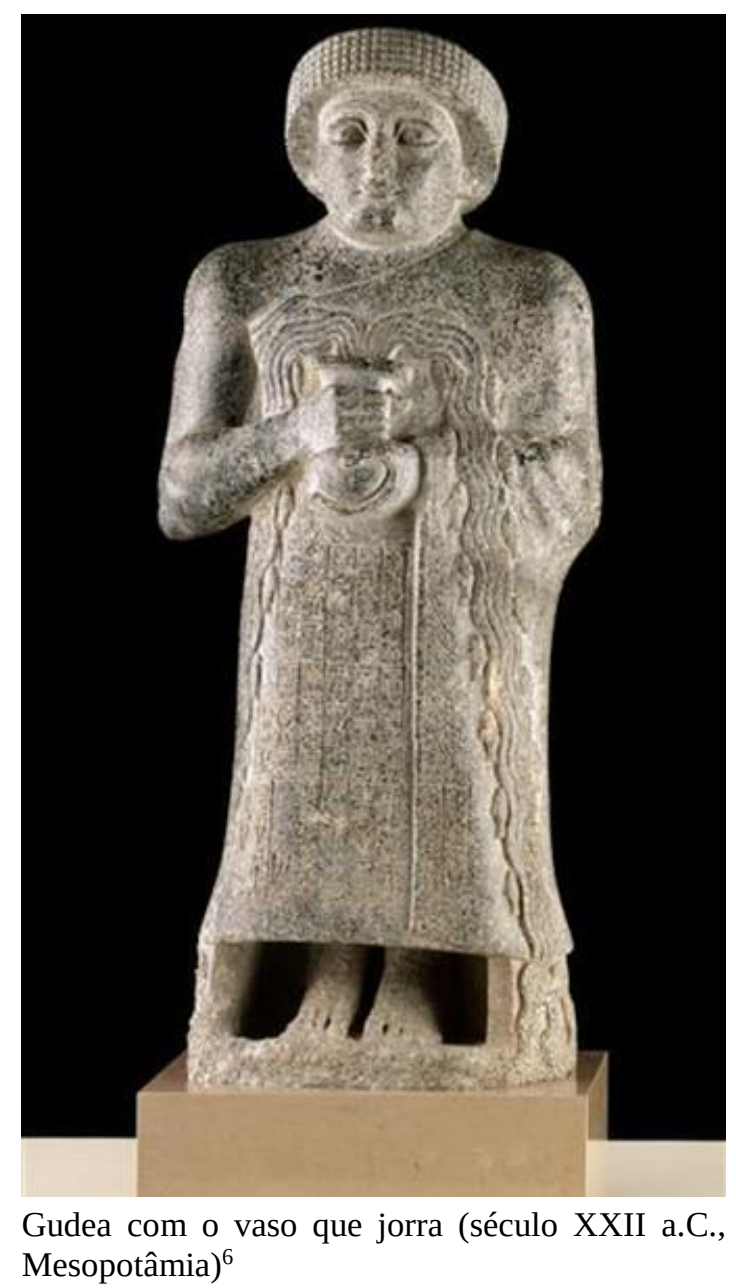

Ao fornecer água e peixes, o vaso aparece como símbolo de fecundidade, e a homenagem a Geshtinanna sugere a água como provedora de vitalidade capaz de reanimar o povo e a lei. Como se vê, o legislador assume a função de mediador entre o homem e a divindade, responsável por distribuir a linfa vital, na qual se compreendem os meios de subsistência para os homens e os preceitos disciplinadores da vida comunitária.

Outro exemplo pode ser encontrado no Velho Testamento dos hebreus. Moisés é o arquétipo do pastor de homens, legislador responsável por intermediar as relações da comunidade com a

\footnotetext{
${ }^{6}$ Fotografia de autoria de Franck Raux. Disponível em: <https://goo.gl/DwEHJC>. Acesso em: 24 ago. 2015.
} 
divindade, provendo alimento e lei para a manutenção de sua vida natural e política. São inúmeras as relações simbólicas que estabelece com a água no texto sagrado, a começar por seu nome: após o rei do Egito ordenar às parteiras que matem todos os filhos dos hebreus, lançando-os ao rio (Êxodo, 1:1622), é salvo pela filha do Faraó, que lhe atribui o seu nome - “retirado da água”, na etimologia hebraica (Êxodo, 2:1-10). Após ser salvo, Moisés comete homicídio e é obrigado a fugir, encontrando moradia perto de um poço em Midiã, o que lhe propicia a oportunidade de saciar a sede do rebanho das filhas do sacerdote Jetro e casar-se com uma delas (Êxodo, 2:11-19). Escolhido por Deus para tirar do Egito os filhos de Israel (Êxodo, 3:10), recebe a incumbência de convencer o faraó com dez pragas, das quais a primeira foi a transformação das águas do rio Nilo em sangue, com a morte de todos os peixes (Êxodo, 7:20-21). Quando o faraó finalmente permite a saída dos hebreus, são perseguidos por seu exército até o Mar Vermelho, cujas águas são separadas por Deus após Moisés estender a sua mão por sobre o mar (Êxodo, 14:21), o que permite que escapem. Começa então o período da peregrinação pelo deserto, durante o qual Moisés intervém perante o Senhor para obter para o povo pão e água (Êxodo, 16:15; 17:6) e recebe de suas próprias mãos as tábuas da lei (Êxodo, 31:18). Então, chegando ao deserto de Zim, a falta de água volta a inquietar o povo, o que leva a nova intervenção de Moisés perante o Senhor, e à sua punição de jamais pisar na terra prometida:

Chegando os filhos de Israel, toda a congregação, ao deserto de Zim, no mês primeiro, o povo
ficou em Cades; e Miriã morreu ali, e ali foi sepultada. E não havia água para a congregação;
então se reuniram contra Moisés e contra Arão. E o povo contendeu com Moisés, dizendo:
Quem dera tivéssemos perecido quando pereceram nossos irmãos perante o Senhor! E por
que trouxestes a congregação do Senhor a este deserto, para que morramos aqui, nós e os
nossos animais? E por que nos fizestes subir do Egito, para nos trazer a este lugar mau? Lugar
onde não há semente, nem de figos, nem de vides, nem de romãs, nem tem água para beber.
Então Moisés e Arão se foram de diante do povo à porta da tenda da congregação, e se
lançaram sobre os seus rostos; e a glória do Senhor lhes apareceu. E o Senhor falou a Moisés
dizendo: Toma a vara, e ajunta a congregação, tu e Arão, teu irmão, e falai à rocha, perante
os seus olhos, e dará a sua água; assim lhes tirarás água da rocha, e darás a beber à
congregação e aos seus animais. Então Moisés tomou a vara de diante do Senhor, como lhe
tinha ordenado. E Moisés e Arão reuniram a congregação diante da rocha, e Moisés disse-
lhes: Ouvi agora, rebeldes, porventura tiraremos água desta rocha para vós? Então Moisés
levantou a sua mão, e feriu a rocha duas vezes com a sua vara, e saiu muita água; e bebeu a
congregação e os seus animais. E o Senhor disse a Moisés e a Arão: Porquanto não crestes
em mim, para me santificardes diante dos filhos de Israel, por isso não introduzireis esta
congregação na terra que lhes tenho dado. Estas são as águas de Meribá, porque os filhos de
Israel contenderam com o Senhor; e se santificou neles (Números 20:1-13).

A grave punição imposta a Moisés é motivada por duas faltas: a primeira foi não confiar na palavra do Senhor, batendo na rocha duas vezes quando havia recebido a clara instrução de apenas lhe falar; a segunda foi não glorificar o Senhor, assumindo em seu próprio nome a autoridade divina ao falar, em primeira pessoa, que tiraria água da rocha para o povo. Em ambos os comportamentos se percebe a violação de uma proibição fundamental: a de não usurpar a autoridade divina no governo 
do povo. O pastor de homens provê, mas não provê em nome próprio: pão e água, fé e lei, não provêm de si, mas da divindade, guardiã última do rebanho confiado aos cuidados do Rei-pastor.

Desse modo, a relação pastoral é uma relação que se estabelece essencialmente, em sua forma plena e positiva, como relação entre Deus e os homens - somente intermediada pelo governante. O exemplo hebreu é claro: na fonte de Meribá não é de Moisés que se origina a água vital; ele apenas pede, em nome do povo, a Deus, que decide por si só se irá fornecê-la ao povo escolhido. Não é o Rei-pastor quem satisfaz as necessidades da comunidade; ele distribui o alimento, a água e a lei provenientes de outro lugar, criadas por uma autoridade superior. Desse modo, o legislador não se apresenta como governante laico, mas sempre como intermediário, incapaz de criar a lei e responsável por transmiti-la, após recebê-la, literalmente, do “dedo de deus” (Êxodo, 31:18). O profeta-governante não é a fonte da água, como também não é a fonte da lei; apenas fende a rocha, permitindo que a vontade de deus se manifeste.

Também entre os romanos a metáfora da fonte é empregada para expressar o mesmo tipo de relação. Nas lendas sobre o período arcaico é o segundo rei de Roma, Numa Pompílio (que teria governado entre 717 a.C. e 673 a.C.), o responsável por dar à cidade um conjunto de leis, reformando a religião. Contudo, não é ele quem as cria: Tito Lívio conta que Numa costumava se encontrar em um bosque cruzado por um rio com a ninfa Egéria, que o instruiu em todos os segredos da religião:

Havia um bosque cruzado por um rio que fluía perene, brotando de uma gruta escura. Aqui se retirava frequentemente Numa, em solidão, como se fosse se encontrar com a deusa, e consagrou o bosque à Camaenae, porque foi ali que tiveram lugar seus encontros com sua esposa Egéria (LÍVIO, 2013, 1.21)

Assim, sob orientação de Egéria nomeou flâmines para representarem os deuses Júpiter, Marte e Quirino, promoveu uma reforma do calendário e das festas religiosas, instituiu as virgens vestais, o colégio dos feciali, o colégio dos salii, o colégio dos pontífices, construiu templos à Fé e ao Término e distribuiu a plebe por ofícios, acabando com a distinção entre sabinos e romanos. Percebe-se novamente a concepção do Rei-pastor como responsável por guiar o rebanho, intermediando a relação entre os homens e os deuses e assegurando, assim, a saúde natural e política da comunidade. Quanto à saúde natural, a lenda narra como Numa salvou Roma de uma epidemia graças à intervenção de Egéria, que ele honrou com a criação do colégio dos salii e a consagração (novamente!) de uma fonte (PLUTARCO, 1821, p. 13). Quanto à saúde política, instituiu o Palácio Real e se tornou Pontífice Máximo, passando a maior parte do seu tempo instruindo os sacerdotes

\footnotetext{
7 Tradução livre da edição espanhola: "Había un bosque en medio de un arroyo que fluía perenne, brotando de una cueva oscura. Aquí se retiraba frecuentemente Numa, en soledad, como si se fuera a encontrar con la diosa, y consagró el bosque a la Camaenae, porque fue allí donde tuvieron lugar sus encuentros con su esposa Egeria”.
} 
sobre as coisas divinas e humanas - justamente os pontífices cujas respostas e rituais viriam a constituir a tradição que formaria o primeiro ius civile dos romanos:

Assim que organizou o sacerdócio, edificou junto ao templo de Vesta a que se chamou Régia, isto é, Casa ou Palácio Real, e ali passava a maior parte do tempo ocupado com as coisas sagradas ou instruindo os sacerdotes, ou entretendo-se com eles na investigação das coisas relativas à divindade (PLUTARCO, 1821, p. 14)

Como se vê, a associação realizada pelos romanos entre a figura do governante e a metáfora da fonte não se dá por uma associação entre a sua autoridade e o poder de criar direito, mas por seu papel de mediador entre a divindade e os homens. O reconhecimento de Numa como legislador não implica seu reconhecimento como fonte do direito; apenas decorre do fato de que a sua sabedoria o torna apto a ser amado por Egéria, e dela receber as leis que regerão a comunidade política. A metáfora da “fonte sagrada” não indica a gênese do direito, mas a possibilidade de conhecimento de um conjunto de leis eternas, imutáveis e incriadas, transmitidas aos homens pela generosidade dos deuses. O direito dado pelo governante não decorre de sua vontade, mas da revelação das regras imutáveis que vivificam a comunidade.

O exemplo permite a conclusão de que na cultura jurídica romana a "fonte” não cria direito. Trata-se de mero caminho de passagem que permite o conhecimento de um direito proveniente de outro local. Essa concepção permite compreender por que razão apenas muito tarde, na história do pensamento jurídico romano, a metáfora da fonte começa a ser empregada: a expressão aparece pela primeira vez entre os romanos no século I a.C., quando Tito Lívio qualifica a Lei das XII Tábuas, em sua História de Roma, como fons omnis publici privatique iuris, "fonte de todo o direito público e privado":

Quando parecia que haviam sido suficientemente modificadas de acordo com o que todos haviam expressado, as Leis das Dez Tábuas foram aprovadas pelos comícios centuriatos. Mesmo na enormidade da legislação atual, em que as leis se empilham umas sobre as outras em um confuso monte, ainda são a fonte de todo o direito público e privado (LíVIO, 2013, $3.34)^{9}$.

A estrutura sintática do texto demonstra com clareza que Lívio não pretende atribuir à Lei das XII Tábuas uma função produtora do direito objetivo romano. Pelo contrário, trata-se de

\footnotetext{
${ }^{8}$ Tradução livre da edição espanhola: “Luego que hubo arreglado los sacerdocios, edificó junto al templo de Vesta la que se llamó Regia, esto es, Casa o Palacio Real, y allí pasaba la mayor parte del tiempo ocupado en las cosas sagradas o instruyendo a los sacerdotes, o entreteniéndose con ellos en la investigación de las cosas tocantes a la divinidad".

${ }^{9}$ Tradução livre da edição espanhola: "Cuando parecía que habían sido suficientemente modificadas de acuerdo con lo que todos habían expresado, las Leyes de las Diez Tablas fueron aprobadas por los comicios centuriados. Incluso en la enormidad de la legislación actual, donde las leyes se apilan unas sobre otras en un confuso montón, aún son la fuente de toda la jurisprudencia pública y privada".
} 
reconhecê-la como elemento vivificante do ordenamento jurídico, que, se por um lado, dela recebe a vitalidade que permite a sua existência, por outro não se encerra em seu texto normativo, abarcando uma série de manifestações distintas - como indica a referência à “enormidade da legislação atual, em que as leis se empilham, umas sobre as outras, em um confuso monte”.

Também no século I a.C. a expressão “fonte” é empregada no livro de Cícero Sobre a Lei. Novamente, não para se referir a uma causa genética criadora do direito, mas ao seu fundamento, à sua razão de ser, considerando como fons legum os “princípios da moral” e as "sublimes doutrinas da filosofia” (em vez do edito do pretor e da Lei das XII Tábuas):

Pois, acredite em minha palavra, em nenhum outro tipo de discussão podem ser melhor apresentados aquilo que foi concedido ao homem pela natureza, e a grande capacidade para os empreendimentos mais nobres que foi implantada na mente humana, para os quais nascemos e fomos enviados ao mundo, e que bela associação, que sociedade natural une os homens em caridades recíprocas: e quando tivermos explicado estes grandes e universais princípios da moral, então a verdadeira fonte das leis e dos direitos pode ser encontrada (CÍCERO, 1853, p. 405) ${ }^{10}$.

Todavia, Lívio e Cícero ainda não são propriamente juristas, e não proferem seus discursos do ponto de vista do saber jurídico. Discorrem sobre o direito com competência, mas da perspectiva do historiador e do filósofo - portanto, sem uma preocupação explícita com a identificação dos locais de surgimento das prescrições jurídicas vinculantes. Esse tipo de preocupação apenas começa a aparecer ao final do Principado, quando tem início o processo de concentração do poder de criação de normas jurídicas na autoridade do imperador. Assim, é somente em II d.C. que Pompônio irá se referir à Lei das XII Tábuas, no Enchiridion, como o local de onde "flui" o ius civile (lege duodecim tabularum ex his fluere coepit ius civile), e a partir do qual são compostas as ações da lei:

D.1.2.2.6. [Pompônio] [...] E assim quase ao mesmo tempo nasceram estes três direitos: o direito da Lei das XII Tábuas, das quais o ius civile começou a fluir e, destas mesmas, foram compostas as ações da lei. (MADEIRA, 2012, p. 28) $)^{11}$

Não se trata, porém, de identificá-la como causa genética de criação do ius civile. Pompônio deseja identificar o primeiro passo de um longo desenvolvimento histórico, a partir do qual o ius civile foi se configurando em estratos distintos sobrepostos. Como explicam Cerami e Purpura (2007, p. 195), aqui a metáfora hídrica não se refere à criação do direito em uma perspectiva etiológico-

\footnotetext{
10 Tradução livre da edição inglesa: "For, take my word for it, in no kind of discussion can it be more advantageously displayed how much has been bestowed upon man by nature, and how great a capacity for the noblest enterprises is implanted in the mind of man, for the sake of cultivating and perfecting which we were born and sent into the world, and what beautiful association, what natural fellowship, binds men together by reciprocal charities: and when we have explained these grand and universal principles of morals, then the true fountain of laws and rights can be discovered".

${ }^{11}$ No original, em latim: "Et ita eodem paene tempore tria haec iura nata sunt: lege duodecim tabularum ex his fluere coepit ius civile, ex isdem legis actiones compositae sunt”.
} 
derivativa (de causalidade), mas indica uma perspectiva histórico-enumerativa (cronológica) da ordem jurídica. A explicação também esclarece por que a metáfora da "fonte” é tão pouco utilizada entre os juristas romanos, que preferem a expressão “meios de constituição do direito” (viae iuris constituendi): o verbo constituere permite a referência ao processo factual de formação do ius civile de modo estrutural-funcional, em vez de determinativo-preceptivo. É o que se percebe neste trecho de Pompônio:

D.1.2.2.11. [Pompônio] Por fim, como os meios de constituição do direito tivessem passado a poucos, conforme o que os próprios fatos ditaram, ocorreu, por partes, que se fizesse necessário à res publica que ela fosse vigiada por um só (pois o senado não podia de modo absolutamente igual administrar dignamente todas as províncias). Por conseguinte, constituído um príncipe, foi dado a ele o direito, a fim de que o que ele elaborasse fosse confirmado (MADEIRA, 2012, p. 31) ${ }^{12}$.

O mesmo pode ser verificado na famosa classificação de Gaio, que ao indicar os elementos que “constituem o direito do povo romano” (constant autem iura Populi Romani) organiza-os em uma articulação histórica do processo de formação do ius civile - embora a tradução portuguesa da Fundação Calouste Gulbenkian tenha preferido atualizar a expressão e traduzi-la como "fontes do direito do povo romano":

I.2. As fontes do [rectius: Constituem o] direito do povo romano são: as leis, os plebiscitos, os senátus-consultos, as constituições imperiais, os editos dos magistrados que possuem o direito de emitir editos, as respostas dos jurisprudentes (GAIO, 2010, p. 77) ${ }^{13}$.

Apesar das inferências errôneas que a tradução imprecisa pode motivar, é somente na virada para o século III d.C. que começa a aparecer, entre os romanos, a ideia de uma relação de causalidade genética entre o direito, como produto, e as suas fontes, como fatores de produção. Então o ius é expressamente separado de seus elementos formadores, identificados por Papiniano com a expressão ex venit, "provém de":

D.1.1.7. [Papiniano] Ius civile é aquilo que provém da lei, dos plebiscitos, dos senatusconsultos, dos decretos dos príncipes e da autoridade dos jurisprudentes (MADEIRA, 2012, p. 23) $)^{14}$.

Não por acaso, essa é a mesma época em que o príncipe começa a concentrar poder político e autoridade para criar direito por meio de constituições imperiais. Nesse momento a visão

\footnotetext{
${ }^{12}$ No original, em latim: “Novissime sicut ad pauciores iuris constituendi vias transisse ipsis rebus dictantibus videbatur per partes, evenit, ut necesse esset rei publicae per unum consuli (nam senatus non perinde omnes provincias probe gerere poterat): igitur constituto principe datum est ei ius, ut quod constituisset, ratum esset”.

${ }^{13}$ No original, em latim: "Constant autem iura populi Romani ex legibus, plebiscitis, senatus consultis, constitutionibus principum, edictis eorum, qui ius edicendi habent, responsis prudentium”.

${ }^{14}$ No original, em latim: "Ius autem civile est, quod ex legibus, plebis scitis, senatus consultis, decretis principum, auctoritate prudentium venit”.
} 
ritualística-instrumental do direito já havia sido superada por uma concepção formal-abstrata, o que implica a possibilidade de produção e inovação das normas jurídicas. Como apontam Cerami e Purpura (2007, p. 203), o venire ex de Papiniano, simétrico mas distinto do fluere ex de Pompônio, indica uma verdadeira relação de causalidade entre os elementos componentes do ius civile e o próprio ius civile como seu produto final.

Todavia, da adoção de uma perspectiva que concebe a possibilidade de produção do direito e a identificação de suas causas geradoras não decorre a identidade semântica com a metáfora contemporânea das fontes do direito. Embora o pensamento jurídico romano passe a considerar possível, a partir do século III, a identificação dos locais de onde surge a prescrição jurídica, a metáfora da fonte continua mantendo o seu significado antigo de espaço de passagem, abertura percorrida pela água originada alhures, para ser distribuída à cidade de modo a vivificar a ordem social. Se na transição do Principado para o Dominato um dos últimos grandes juristas de Roma pode

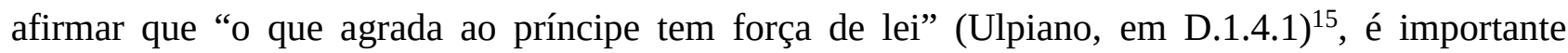
compreender que isso não significa que o príncipe possa criar direito com base em sua vontade arbitrária, mas apenas que a comunidade política reconhece a sua capacidade superior de identificar as normas decorrentes da ordem natural, impondo-as para o bem da comunidade. E assim permanece até o final do Dominato, quando se escrevia sobre o pórtico da Escola de Direito de Bizâncio o seguinte aviso: "Sou um lugar consagrado às leis. Daqui brota uma fonte rica de direito romano, que flui eternamente para todos, e oferece os seus fluxos à juventude aqui recolhida” ${ }^{\prime 6}$.

\subsection{PREMISSA TEÓRICA 2: A FONTE COMO DISPUTA}

Compreendendo-se que as possibilidades de significado atribuídas à expressão "fonte do direito” pela sociedade romana antiga são radicalmente distintas das nossas, fica evidente a dificuldade de sua utilização para a adequada compreensão das suas características. Não obstante, o único instrumento de que dispomos para compreender a realidade que nos cerca continua sendo o aparato teórico e conceitual fornecido por nossa própria cultura, de modo que não temos alternativa para olhar para o passado, a não ser através das lentes de nossa própria visão de mundo. Isso faz com

\footnotetext{
15 “D.1.4.1. [Ulpiano] O que agrada ao príncipe tem força de lei. Isso porque o povo, por uma lei régia que foi promulgada sobre o imperium dele, confere a ele todo o seu imperium e sua potestas" (MADEIRA, 2012, p. 61). No original, em latim: "Quod principi placuit, legis habet vigorem: utpote cum lege regia, quae de imperio eius lata est, populus ei et in eum omne suum imperium et potestatem conferat”.

${ }^{16}$ Recordada, novamente, por Cerami e Purpura. Na citação dos autores, que a traduziram do grego para o italiano: “Sono un luogo consacrato alle leggi. Da qui scaturisce una fonte ricca di diritto romano che scorre eternamente per tutti e che offre tutto il suo flusso alla gioventù qui raccolta” (2007, p. 203).
} 
que a reflexão histórica seja sempre analógica: afinal, inevitavelmente depende de palavras contemporâneas, que se referem a fenômenos contemporâneos, para descrever fenômenos antigos que apenas em grau muito abstrato podem ser considerados semelhantes aos que observamos no presente ${ }^{17}$.

Como em todo raciocínio analógico, a qualidade deste também depende essencialmente da precisão na identificação da semelhança relevante existente entre os dois entes comparados, o que, por sua vez, depende de uma profunda capacidade de abstração de suas características fundamentais. A observação da aparência imediata impede qualquer comparação, pois a realidade é múltipla e plural, e em suas manifestações concretas todos os entes são compostos por uma infinidade de detalhes e particularidades que os tornam absolutamente incomparáveis entre si. Isso faz com que toda comparação pressuponha uma simplificação, resultado de um processo de abstração que encontre características muito gerais passíveis de serem igualmente atribuídas a dois entes distintos - ainda que em suas manifestações concretas essas características apresentem peculiaridades jamais reconduzíveis a uma unidade essencial.

Este é o difícil trabalho posto diante do historiador do direito: se desejamos preservar a utilidade heurística dos instrumentos fornecidos pela dogmática jurídica contemporânea para a compreensão de fenômenos jurídicos do passado (e desejamos, pois não temos outros), devemos despi-los de seus elementos acessórios, concretos, historicamente situados, para submetê-los a um trabalho de abstração que seja capaz de encontrar, não a sua essência (afinal, inexistente, e sempre historicamente construída), mas pelo menos um núcleo semântico fundamental, suficientemente maleável para permitir a comunicação com as culturas do passado, mas minimamente sólido para que o diálogo não se evapore em uma névoa destituída de significado no presente. A linguagem e a teoria não exaurem o real; apenas permitem a apreensão provisória de alguns de seus aspectos, intermediando as conexões possíveis entre passado e presente.

Assim, se continuamos a depender do inapropriado conceito de fontes do direito para observarmos e compreendermos certos aspectos do direito da sociedade romana antiga, é imprescindível esclarecer com exatidão a quê nos referimos quando o empregamos, sob pena de as lentes do presente se tornarem opacas, obscurecerem a nossa visão e nos apresentarem somente o reflexo, confortável e tranquilizador, de um par de olhos já muito bem conhecidos - os nossos próprios. Para isso precisamos ultrapassar a complexa construção teórica do direito contemporâneo

\footnotetext{
17 Por outro lado, é sempre bom também recordar que compreendemos a realidade contemporânea com base em um vocabulário herdado do passado, o que significa que a tradução analógica é uma via de mão dupla.
} 
para encontrarmos, na realidade concreta a que o conceito se refere, elementos que permitam alguma comparação com a realidade do direito romano antigo.

Um belo exemplo de esforço realizado nesse sentido pode ser encontrado na Introdução Crítica ao Direito realizada por Michel Miaille: com o objetivo de superar a estrita descrição teórica para alcançar a realidade material do direito contemporâneo (MIAILLE, 2005, p. 23), o autor ultrapassa a enumeração dogmática dos modos de formalização das prescrições jurídicas e busca encontrar os fenômenos e ideias a que o termo se refere para enunciar as suas prescrições, alcançando os conflitos sociais subjacentes a esta formalização (MIAILLE, 2005, p. 197). Mas a proposta do autor não se exaure na indicação dos "fatores que influenciam uma legislação", como poderia sugerir uma perspectiva sociológico-jurídica. Pelo contrário, pretende abarcar forma e conteúdo para compreender a lógica inerente ao sistema jurídico, capaz de elucidar tanto o conteúdo das prescrições jurídicas quanto o modo como elas são produzidas concretamente - assim como a travessia realizada pelo direito desde os conflitos da realidade material até a sua formalização em prescrição abstrata.

Afinal, o processo de criação do direito em um determinado contexto é sempre condicionado pelo equilíbrio dos poderes em conflito na ordem institucional em que os juristas operam, e pelas concepções políticas que caracterizam um determinado território. Desse modo, a estruturação de um sistema formal de fontes do direito não é um problema meramente dogmático-jurídico, mas teóricopolítico, cuja resolução depende dos sujeitos a quem uma determinada ordem jurídico-política reconhece o poder de criar o direito. Para isso é preciso, como sugere Bourdieu (2004, p. 211), compreender a autoridade jurídica como resultado de um campo cuja racionalidade específica é duplamente determinada: por um lado, pelas relações de força específicas que lhe conferem estrutura e orientam suas lutas de concorrência; e por outro lado, pela lógica interna do pensamento jurídico que delimita, em cada momento e a cada aplicação, o espaço dos possíveis e o universo das soluções jurídicas aceitáveis como tal.

Em outras palavras, além de retomar a tese de que a estruturação de um sistema de fontes do direito depende da materialidade dos conflitos sociais pelo poder de estabelecer o direito, Bourdieu ressalta a necessidade de se observar que a mera estruturação desse sistema formal não exaure o trabalho de constituição do ordenamento, ainda dependente, a cada momento e a cada aplicação, também das disputas que ocorrem no interior do próprio sistema (no pensamento jurídico) pelo poder de delimitar o universo de possibilidades jurídicas e definir a amplitude social e semântica do "direito de dizer o direito”. Explica o autor:

A significação prática da lei não se determina realmente senão na confrontação entre diferentes corpos animados de interesses específicos divergentes (magistrados, advogados, 
notários, etc.), eles próprios divididos em grupos diferentes animados de interesses divergentes, e até mesmo opostos, em função sobretudo da sua posição na hierarquia interna do corpo, que corresponde sempre de maneira bastante estrita à posição da sua clientela na hierarquia social. Segue-se daqui que uma história social comparada da produção jurídica e do discurso jurídico sobre esta produção deveria esforçar-se por pôr metodicamente em relação as tomadas de posição nessa luta simbólica e as posições na divisão do trabalho jurídico (BOURDIEU, 2004, p. 217-218).

Ora, se existe alguma analogia possível entre a metáfora contemporânea e a metáfora antiga das fontes do direito, ela está justamente no fato de sua identificação como racionalização teórica do processo material de formalização jurídica das disputas políticas em torno das regras de organização e disciplinamento da vida social. Desse modo, se ainda tem utilidade a metáfora das fontes do direito para a compreensão do direito romano antigo, ela depende de um emprego dinâmico, capaz de levar em consideração o jogo real de poderes em disputa e os efeitos sociais da concentração do poder de criação jurídica em determinados locais da sociedade romana antiga.

Com isso se torna possível tratar de outra maneira a investigação sobre as fontes do direito romano; não se trata mais, agora, de se descrever os focos de autoridade capazes de estabelecer prescrições jurídicas e as modalidades formais de exercício legítimo do seu poder político - o que seria um anacronismo imperdoável. Mas de se identificar os modos específicos como uma determinada formação social organiza os seus conflitos sociais e promove a formalização de suas prescrições jurídicas. Essa perspectiva permite superar a concepção dogmático-formal de fontes do direito como loci de autoridade capazes de estabelecer prescrições jurídicas, em prol de uma nova concepção, histórico-material, que as compreende como processos sociais de formalização de conteúdos jurídicos em uma comunidade determinada. Em outras palavras, a discussão é transposta do campo da dogmática transcendental para o da história empírica, e a metáfora deixa de ser um anacronismo para se tornar um importante instrumento heurístico empregado na compreensão do ordenamento jurídico romano.

Afinal, o significado efetivo do direito e a estruturação de suas fontes não são dados sem esforço, mas construídos como resultado de uma disputa política real, existente não apenas no campo pré-jurídico da política, mas também no interior do próprio pensamento jurídico. É evidente, portanto, que um estudo sobre a classificação das fontes do direito romano deve levar essas disputas em consideração para entender adequadamente o seu significado, enfiando as mãos na realidade histórica para compreender como o jogo de fontes reflete uma disputa concreta pelo direito de dizer o direito, e quais são os efeitos dessa disputa na realidade social. Para isso, não pode se limitar a enumerá-las, conceituando-as formalmente e indicando a sua prevalência em determinados períodos da civilização romana. Em vez disso, deve reconhecer que a sua própria enumeração ocorre no contexto de uma 
disputa política, e que para compreender com precisão o seu significado deve levar em consideração a complexa realidade social, política e econômica de que fazem parte.

\section{CONCLUSÃO}

É possível que este trabalho desaponte alguns de seus leitores, por deixar de apresentar uma estrutura ordenada das fontes do ordenamento jurídico romano. A ausência se deve, é claro, ao fato de não ser este o objetivo da pesquisa, mas principalmente ao fato de essa não ser uma resposta que possa ser fornecida a priori, com a apresentação de um sistema geral nos moldes dos que têm sido elaborados pela tradição romanística contemporânea. O problema da identificação das fontes do direito romano, compreendidas como meios disponíveis para o processo de formalização jurídica de interesses sociais em disputa, só pode ser resolvido a posteriori, como resultado de uma complexa investigação histórico-jurídica que seja capaz de identificar:

a) Os conflitos extrajurídicos que delimitam o campo atribuído à esfera de regulação jurídica em cada momento histórico determinado;

b) O significado particular atribuído à metáfora da fonte e o contexto de seu uso social e jurídico em cada contexto histórico determinado;

c) As disputas intrajurídicas pelo direito de dizer o direito entre os vários partícipes do processo de elaboração e interpretação das prescrições jurídicas vinculantes; e, finalmente, d) As alternativas disponibilizadas pelo campo jurídico para a realização do processo material de formalização jurídica dos interesses sociais em disputa.

Com isso, o problema da identificação das fontes do direito na sociedade romana antiga deixa de ser o ponto de partida para se tornar o resultado final da pesquisa histórico-jurídica, que deverá investigar, para cada contexto histórico, as condições materiais de formalização do direito disponíveis para a sociedade romana antiga. Como se vê, se a metáfora da fonte e os esquemas classificatórios gerais ainda nos servem, servem-nos somente como instrumento heurístico: ferramentas dogmáticas a permitirem uma primeira aproximação em relação aos sistemas normativos do passado, mas que não exaurem em si a sua compreensão, inseparável da compreensão dos conflitos políticos e das disputas jurídico-normativas existentes em cada formação social concreta.

Uma abordagem como esta não é capaz de fornecer respostas claras e definitivas, mas pode auxiliar na compreensão do duplo aspecto constituinte-constituído das fontes do direito romano; e 
assim, poderá nos ajudar a entender melhor o emaranhado processo histórico de construção de um ordenamento jurídico autônomo pela sociedade romana antiga.

\section{REFERÊNCIAS}

ALBERGARIA, Bruno. Histórias do direito: evolução das leis, fatos e pensamentos. 2. ed. São Paulo: Atlas, 2012.

ALVES, José Carlos Moreira. Direito romano. 15. ed. Rio de Janeiro: Forense, 2012.

BOURDIEU, Pierre. O poder simbólico. Tradução Fernando Tomaz. 7. ed. Rio de Janeiro: Bertrand Brasil, 2004.

CERAMI, Pietro; PURPURA, Gianfranco. Profilo storico-giurisprudenziale del diritto pubblico romano. Torino: G. Giappichelli Editore, 2007.

CHAMOUN, Ebert. Instituições de direito romano. 3. ed. Rio de Janeiro: Revista Forense, 1957.

CRETELLA JÚNIOR, José. Curso de direito romano: o direito romano e o direito civil brasileiro no Novo Código Civil. Rio de Janeiro: Forense, 2009.

FILARDI LUIZ, Antônio. Curso de direito romano. São Paulo: Atlas, 1999.

GAIO. Instituições - direito privado romano. Tradução J. A. Segurado Campos. Lisboa: Fundação Calouste Gulbenkian, 2010.

GIORDANI, Mário Curtis. Iniciação ao direito romano. Rio de Janeiro: Lumen Juris, 1991.

JUSTO, A. Santos. Direito privado romano - I: parte geral. Introdução. Relação jurídica. Defesa dos Direitos. 3. ed. Coimbra: Coimbra Editora, 2006.

LÍVIO, Tito. La Historia de Roma. Tradução Antonio Diego Duarte Sanchez. Murcia, 2013. Disponível em: <https://goo.gl/Psz8To>. Acesso em: 6 out. 2015.

MADEIRA, Hélcio Maciel França (Org.). Digesto de Justiniano, liber primus - introdução ao direito romano. Tradução Hélcio Maciel França Madeira. 6. ed. São Paulo: Revista dos Tribunais, 2012.

MARKY, Thomas. Curso elementar de direito romano. 8. ed. São Paulo: Saraiva, 2010.

MEIRA, Sílvio. Curso de direito romano: história e fontes. São Paulo: Saraiva, 1975.

MIAILLE, Michel. Introdução crítica ao direito. Tradução Ana Prata. 3. ed. Lisboa: Estampa, 2005.

PLUTARCO, Mestrio. Vida de Numa Pompilio. Tradução Antonio Ranz Romanillos. 1821. Disponível em: <https://goo.gl/HrsTNy>. Acesso em: 6 out. 2015. 
REALE, Miguel. Lições preliminares de direito. 25. ed. São Paulo: Saraiva, 2001.

SCHIAVONE, Aldo. Ius: l'invenzione del diritto in Occidente. Torino: Giulio Einaudi Editore, 2005.

Walter Guandalini Junior

Professor Adjunto do Departamento de Direito Privado no Setor de Ciências Jurídicas da Universidade Federal do Paraná (UFPR). Mestre e Doutor em Direito do Estado pela UFPR. E-mail: prof.walter.g@gmail.com 